\title{
A review of the positive and negative effects of cardiovascular drugs on sexual function: a proposed table for use in clinical practice
}

\author{
M. P. J. Nicolai • S. S. Liem • S. Both • R. C. M. Pelger • \\ H. Putter • M. J. Schalij • H. W. Elzevier \\ Published online: 24 October 2013 \\ (C) The Author(s) 2013. This article is published with open access at Springerlink.com
}

\begin{abstract}
Several antihypertensive drugs, such as diuretics and $\beta$-blockers, can negatively affect sexual function, leading to diminished quality of life and often to noncompliance with the therapy. Other drug classes, however, such as angiotensin II receptor blockers (ARBs) are able to improve patients' sexual function. Sufficient knowledge about the effects of these widely used antihypertensive drugs will make it possible for cardiologists and general practitioners to spare and even improve patients' sexual health by switching to different classes of cardiac medication. Nevertheless, previous data (part I) indicate that most cardiologists lack knowledge about the effects cardiovascular agents can have on sexual function and will thus not be able to provide the necessary holistic patient care with regard to prescribing these drugs. To be able to improve healthcare on this point, we aimed to provide a practical overview, for use by cardiologists as well as other healthcare professionals, dealing with sexual dysfunction in their clinical practices. Therefore, a systematic review of the
\end{abstract}

M. P. J. Nicolai $(\varangle) \cdot$ R. C. M. Pelger $\cdot$ H. W. Elzevier

Department of Urology, Leiden University Medical Center, PO box 9600, 2300 RC Leiden, the Netherlands

e-mail: mpjnicolai@lumc.nl

\section{S. S. Liem}

Department of Cardiology, Amstelland Hospital, Amstelveen, the Netherlands

\section{S. Both}

Department of Psychosomatic Gynecology and Sexology, Leiden University Medical Center, Leiden, the Netherlands

\section{H. Putter}

Department of Medical Statistics, Leiden University Medical Center, Leiden, the Netherlands

M. J. Schalij

Department of Cardiology, Leiden University Medical Center, Leiden, the Netherlands literature was performed. The eight most widely used classes of antihypertensive drugs have been categorised in a clear table, marking whether they have a positive, negative or no effect on sexual function.

Keywords Sexual dysfunction · Adrenergic beta antagonists · Angiotensin-converting enzyme inhibitors $\cdot$ Angiotensin receptor antagonists - Diuretics - Calcium channel blockers . Hydroxymethylglutaryl-CoA-reductase inhibitors

\section{Introduction}

In the US, the class 'lipid regulators' was the most prescribed drug class in 2010 with 255.5 million prescriptions, beta blockers (plain and in combination) and ACE inhibitors followed in the second and third place with 191.5 million and 168.7 million prescriptions, respectively [1]. In this era of high life expectancies, this therapy will be received during a substantial part of a patient's life [2]. The side effects induced by antihypertensive drugs, including sexual dysfunction, are strongly associated with an impaired quality of life [3].

As many as $70 \%$ of hypertensive patients who experience side effects are non-compliant with their antihypertensive medication and have a 40-60\% higher rate of therapy discontinuation, compared with patients whose quality of life is unaffected [4]. Some classes of antihypertensive drugs have been shown to cause sexual dysfunction, but others have been described to have beneficial effects on sexual health. Physicians and especially cardiologists and general practitioners should be aware of these possible effects of the medication they prescribe, because it makes them able to minimise sexual side effects and maximise quality of life and compliance with therapy. However, previous data obtained by our research group (part I) showed that cardiologists seem to lack sufficient knowledge about the effects cardiac medication can have on sexual function[5]. 
With this review we aimed to provide a practical overview of the available literature regarding the effects of eight widely used classes of cardiovascular agents on sexual function. A clear overview table applicable for both male and female patients is provided for use in clinical settings.

\section{METHODS}

\section{Data sourcing}

A review of the literature was assessed using PubMed and MEDLINE, searching for articles from 1970 to 2012. The search strategy involved the (MeSH) terms 'sexual dysfunction', 'erectile dysfunction', 'sexual side effects', 'side effects', 'sexual adverse effects' and 'adverse effects' consecutively in combination with the MeSH terms: Adrenergic Beta Antagonists, Angiotensin-Converting Enzyme Inhibitors, Angiotensin Receptor Antagonist, Diuretics, Calcium Channel Blockers, Hydroxymethylglutaryl-CoA Reductase inhibitors, Digoxin and more general terms: 'antihypertensive agents', 'beta blocker', 'beta receptor antagonist', 'diuretic', ' $\alpha 1$ adrenoceptor antagonist', 'angiotensin converting enzyme inhibitor', 'angiotensin receptor blocker', 'calcium channel blocker', 'digoxin', 'heart glycosides', 'statins' and 'nitrates'. The last search was conducted in March 2013. The reference list was hand-searched and all relevant studies and reviews were read and reviewed.

\section{Study selection}

All clinical studies reporting about effects on male or female sexual function in relation to a cardiovascular agent were included. These included: animal studies, observational studies, small clinical studies, meta-analyses and randomised controlled trials. Studies not published as full-text articles, single case reports and opinion articles were excluded, as well as articles not written in English. Hard copies of all relevant articles were obtained and read in full. Since the purpose of this review was to provide a positive overview table listing the effects of the eight most widely used cardiac drugs classes for use in clinical practice, we used randomised controlled trials (RCT), double-blind cross-over studies and questionnairebased prospective and retrospective studies in human males and females for the overview tables (Tables 1 and 2).

\section{RESULTS}

\section{$\beta$-blockers}

Several reports have shown serious side effects on sexual function due to the use of (centrally acting) $\beta$-blockers; in particular erectile dysfunction (ED) and loss of desire have been reported [6-9]. One of the proposed mechanisms by which $\beta$-blockers may induce sexual dysfunction is inhibition of the sympathetic nervous system, which is involved in the integration of erection, emission and ejaculation, in the regulation of luteinising hormone secretion and in the stimulation of testosterone release [10]. Indeed, several studies showed a depression in testosterone levels in patients receiving a $\beta$ blockers [11]. In contrast, in other more recent trials no significant adverse effects on sexual function were found with metoprolol [12], propranolol [13], acebutulol [14] and atenolol [15]. In the few studies concerning sexual function in female patients with antihypertensive treatment, metoprolol seems to negatively affect female sexual function index scores (FSFI) [16], especially in comparison with ARBs which seem to ameliorate FSFI scores [17, 18]. After reviewing 15 trials involving 35,000 subjects, Ko et al. reported that the frequency of sexual dysfunction with $\beta$-blockers was $21.6 \%$ and $17.5 \%$ in the placebo group. In addition, $\beta$-blockers were associated with an increased risk of reported impotence in men (RR 1.22; $95 \%$ CI 1.05-1.41). Risk of withdrawal due to a sexual dysfunction was substantially increased (RR 4.89; $95 \%$ CI 2.98-8.03); however, the annual absolute increase in risk of withdrawal was only 2 per 1000 patients (95\% CI 0-5) [19]. Silvestri et al. showed that knowledge and prejudice about side effects of $\beta$-blockers can produce anxiety, which may affect erectile function [14]. A critical review used this study to underpin their doubts about the sexual side effects of $\beta$ blockers [20]. All in all, the final word has not been said about the effect of $\beta$-blockers on sexual function, yet the majority of studies regarding this topic point to negative effects of firstand second-generation $\beta$-blockers. In the guideline of the Heart Foundation, consensus was reached stating that ED is a predictable adverse effect of $\beta$-blockers [21]. The guidelines regarding management of ED published by The British Society for Sexual Medicine highly recommend routine assessment of sexual function prior to initiation of antihypertensive treatment [22]. Furthermore, if patients present with sexual dysfunction during treatment with $\beta$-blockers, a switch to Nebivolol, a novel third-generation $\beta-1$ blocker with a greater degree of selectivity for $\beta-1$ adrenergic receptors, might be a solution. Nebivolol appears to have a very low risk of sexual side effects compared with other agents in its class [23-25]. In a study designed to compare the effects of metoprolol and nebivolol in erectile tissue (MR-NOED), nebivolol was even shown to significantly improve erectile function of hypertensive patients due to nitric oxide modulation [26]. In concordance with the recent review by Baumhakel et al., we can conclude that selective $\beta$-blockers might impair erectile function. However, considering the strong correlation and pathophysiological link between endothelial and erectile function, beta-blockers with beneficial effects on nitric oxide synthase and oxidative stress can improve erectile function [27]. 
Table 1 Overview of studies showing effects of antihypertensive agents on sexual function in men and women

\begin{tabular}{|c|c|c|c|}
\hline Effect on sexual function & Beneficial & Neutral & Negative \\
\hline$\beta$-blockers & $\begin{array}{l}\text { Nebivolol: } \\
\text { Doumas et al., } 2006 \\
\text { Brixius et al., } 2007\end{array}$ & $\begin{array}{l}\text { Medical Research Council, } 1981 \\
\text { Wassertheil-Smoller et al., } 1991 \\
\text { Rosen et al., } 1994 \\
\text { Neaton et al., } 1995 \\
\text { Grimm et al., } 1997 \\
\text { Perez-Stable et al., } 2000 \\
\text { Franzen et al., } 2001\end{array}$ & $\begin{array}{l}\text { Bauer et al., } 1978 \\
\text { Hogan et al., } 1980 \\
\text { Suzuki et al., } 1988 \\
\text { Fogari et al., } 1998 \\
\text { Buchardt et al.,. } 2000 \\
\text { Fogari et al., } 2001 \\
\text { Llisteri et al., } 2001 \\
\text { Fogari et al., } 2002 \\
\text { Ko et al., 2002 } \\
\text { Fogari et al., } 2004(+) \\
\text { Doumas et al., } 2006(\text { ) } \\
\text { Cordero et al., } 2010 \\
\text { Ma et al., 2012 (†) }\end{array}$ \\
\hline Diuretics & & $\begin{array}{l}\text { Croog et al.,1988 } \\
\text { Prisant et al. } 1999 \\
\text { Doumas et al., } 2006(+)\end{array}$ & $\begin{array}{l}\text { Bulpitt et al., } 1973 \\
\text { Hogan et al., } 1980 \\
\text { Medical Research Council,1981 } \\
\text { Curb et al., } 1985 \\
\text { Wassertheil-Smoller et al., } 1991 \\
\text { Chang et al.;, } 1991 \\
\text { Duncan et al., } 1993 \\
\text { Rosen et al., } 1999 \\
\text { Grimm et al., 1997 } \\
\text { Ogihara et al., } 2000 \\
\text { Epstein et al., } 2011\end{array}$ \\
\hline
\end{tabular}

$\alpha$-blockers

ACE inhibitors

ARBs

Calcium channel blocker

Statins
Grimm et al., 1997

Croog et al.,1986 DiBianco et al., 1991 Gupta et al., 1995 Mancini et al., 1996 Gupta et al., 1998

Fogari et al., 2001 Llisteri et al., 2001 Dusing et al., 2003 Yamamoto et al., 2003 Della Chiesa et al., 2003 Fogari et al., 2004 (ㅇ) Ma et al., 2012 ()

Chen et al., 2012

Segal et al., 2012
Lowe et al., 1994

Fawzy et al., 1995

Lepor et al., 1997

Buchardt et al.,. 2000

Llisteri et al., 2001

McConnell et al., 2003

Kirby et al., 2003

De Rijke et al., 2004

Croog et al.,1988

Suzuki et al., 1988

Fletcher et al., 1990

Steiner et al., 1990

Pelmer et al., 1992

Grimm et al., 1997

Fogari et al., 1998

Doumas et al., 2006 (우)

Suzuki et al., 1988

Rosen et al., 1994

Fogari et al., 1998

Fogari et al., 2002

Bohm et al., 2010

Doumas et al., 2006 (ㅇ)

Suzuki et al., 1988

Morrisette et al., 1993

Omvik et al., 1993

Kroner et al., 1993

Grimm et al., 1997

Ogihara et al., 2000

Burnier et al., 2007

Doumas et al., 2006 (ㅇ)

Mastalir et al., 2011

Trivedi et al., 2012
Llisteri et al., 2001

Tanner et al., 1988
Saltzman et al., 2004

Herrmann et al., 2006

Dogru et al., 2008

Gokkaya et al., 2008

Dadkhah et al., 2010 
Table 1 (continued)

\begin{tabular}{|c|c|c|c|}
\hline Effect on sexual function & Beneficial & Neutral & Negative \\
\hline Cardiac glycosides & & $\begin{array}{l}\text { Kley et al., } 1982 \\
\text { Kley et al., } 1984 \\
\text { Bellman et al., } 1984\end{array}$ & $\begin{array}{l}\text { Stoffer et al., } 1973 \\
\text { Neri et al., } 1987 \\
\text { Gupta et al., } 1995\end{array}$ \\
\hline
\end{tabular}

Randomised controlled trials, double-blind crossover studies and questionnaire-based prospective studies

\section{Diuretics}

Diuretics are considered one of the most implicated classes regarding sexual dysfunction. Although the mechanism remains ill-defined [28], striking results with respect of drug treatment in male hypertensive patients were obtained in the Medical Research Council Trial [29], a single-blind study on the basis of 23,582 patients-years. In this trial the prevalence of impotence was measured by questionnaires after 2 years of treatment with propranolol, bendroflumethiazide or placebo. Impotence was mentioned in $10.1 \%$ of the placebo group, in $13.2 \%$ of the propranolol group and in $22.6 \%$ of the bendroflumethiazide group. Incidence of withdrawal from randomised treatment because of impotence (rates per 1000 patient-years) was 0.89 in the placebo group, 5.48 in the propranolol group and 19.58 in the bendroflumethiazide group. The TOMHS trial (The Treatment Of Mild Hypertension Study), a 4-year follow-up, double-blind RTC in 557 men and 345 women, showed that chlortalidone at a dose of $15 \mathrm{mg} /$ day may also be suspected to negatively affect sexual function in men [30]. In the Trial of Antihypertensive Interventions and Management (TAIM), erection-related problems worsened in $28 \%$ of patients receiving chlortalidone, in $11 \%$

Table 2 Practical overview of the effect of commonly prescribed cardiac drugs classes on sexual function

\begin{tabular}{ll}
\hline Drug & Effect \\
\hline$\beta$-blockers & \\
Cardiac glycosides $^{\mathrm{a}}$ & - \\
Diuretics $^{\mathrm{b}}$ & - \\
$\alpha$-blockers $^{\text {ACE inhibitors }}$ & - \\
Calcium channel blockers & \pm \\
Angiotensin receptor blockers & \pm \\
Statins & \pm \\
\hline
\end{tabular}

Information from randomised controlled trials, reviews, double-blind cross-over studies and prospective questionnaire studies in men and women;

${ }^{\text {a }}$ Except for nebivolol, this seems to have positive effects;

${ }^{\mathrm{b}}$ Except for potassium sparing diuretics, which do not appear to cause sexual adverse effects;

- negative effect, \pm no effect, + positive effect of patients receiving atenolol and in $3 \%$ of patients receiving placebo [15].

Smaller studies pointed to hydrochlorothiazide and chlortalidone causing loss of libido and ED [31, 32]. However, sex-life satisfaction was similar for treatment with hydrochlorothiazide (alone or in combination with atenolol) and the more modern treatment with candesartan alone or in combination with the calcium antagonist felodipine [33]. In one of the few studies addressing sexual function in women, thiazide diuretics may be associated with decrease in vaginal lubrication [34]. In addition, although an effective anti-aldosterone agent, spironolactone has a tendency to produce undesirable sexual adverse events; at the standard dose, breast tenderness, gynaecomastia and erectile dysfunction can occur in men, whereas menstrual abnormalities may occur in premenopausal women [35]. These adverse effects are due to binding of spironolactone to progesterone and androgen receptors and represent a substantial reason for drug discontinuation [36]. In the treatment of hypertension, when compared with spironolactone, the selective mineral corticoid receptor antagonist eplerenone provides a reduced incidence of gynaecomastia [37]. The potassium-sparing diuretics amiloride and triamterene do not seem to affect sexual function [35].

$\alpha$-adrenergic antagonists

Since $\alpha$-adrenergic antagonists are first-line therapy for benign prostate hyperplasia (BPH) but only second-line agents for the treatment of hypertension (doxazosin and terazosin), most knowledge regarding sexual adverse effects of $\alpha$ adrenergic antagonists comes from BPH studies. A recent systematic review on the effect of $\alpha 1$-adrenoceptor antagonists on male sexual function was performed by Van Dijk et al.[38]. They showed that $\alpha$-adrenergic antagonists used as treatment for hypertension do not seem to adversely affect sexual desire. The net effect of $\alpha$-adrenergic antagonists on erectile function is likely to depend on the balance between pro-erectile effects in the brain and the penis and anti-erectile effects as a result of blood pressure lowering mechanisms. A 4-year RCT comparing doxazosin in the treatment of hypertension showed that $\alpha$-adrenergic antagonists were not associated with $\mathrm{ED}$; it may even improve pre-existing sexual dysfunction [30]. 
Ejaculatory dysfunction, predominantly the inability to ejaculate and decreased ejaculate volume, is associated with tamsulosin and silodosin, which are superselective $\alpha_{1 \mathrm{~A}}$-adrenergic receptor antagonists. Ejaculatory dysfunction is rare with $\alpha_{1}$-adrenergic receptor antagonists that are not selective for the $\alpha_{1 \mathrm{~A}}$-adrenergic receptor subtype, namely alfuzosin, doxazosin, and terazosin $[39,40]$. In conclusion, the $\alpha$ adrenergic antagonists prescribed as second-line antihypertensive treatment do not seem to affect erectile function or ejaculatory function.

\section{Cardiac glycosides}

In a community-based epidemiological study of 1709 men, analysing data on multiple cardiovascular medications, digoxin use had the highest association with complete ED [41]. The mechanism of action is not completely understood. Early studies linked sexual dysfunction to the hormonal alterations observed with digoxin use [42, 43]. Later studies failed to confirm a relationship with digoxin use and changes in serum hormone levels [44-46]. Another theory proposed is the digoxin-associated inhibition of the corpus cavernosum smooth muscle sodium pump activity, which promotes corporeal contraction and impedes nitric oxide induced relaxation, leading to ED [41].

\section{ACE inhibitors}

Angiotensin-converting enzyme (ACE) inhibitors, particularly captopril, have been associated with improved sexual function [47-49]. It has been suggested that potentially favourable sexual side effects of captopril were secondary to improved cardiac function; however, there are not sufficient data to support this hypothesis [49]. The TOMHS trial showed a significant decrease in sexual activity rate through 24 months in men taking enalapril, compared with placebo [30]. But, in a comparing study between the ACE inhibitor lisinopril and the $\beta$-blocker atenolol, lisinopril only caused a temporary decline in sexual activity. After 4 weeks of treatment, the sexual intercourse rate was reduced but tended to recover with ongoing treatment. Atenolol on the other hand caused a chronic worsening of sexual function [17]. The fact that ACE inhibitors work through other channels than the sympathetic nervous system in lowering blood pressure might in part explain their reduced impact on sexual function. Furthermore, ACE inhibitors have been reported to reverse endothelial dysfunction by preventing the effects of angiotensin II, prolonging the half-life of nitric oxide and decreasing degradation of bradykinin. This last-mentioned is a potent stimulator of nitric oxide and prostacyclin release and may therefore benefit erectile function [50]. It can be concluded that ACE inhibitors have no effect, or may even have a positive effect on sexual function, but their precise role remains to be elucidated.
Angiotensin II receptor antagonists (ARBs)

Multiple studies have shown beneficial effects of ARBs on sexual function. In a cross-over study comparing atenolol with valsartan, valsartan increased sexual activity significantly compared with atenolol (which significantly reduced sexual activity); however, these changes were not significant compared with placebo [11]. Compared with carvedilol, long-term therapy with valsartan was significantly associated with improved sexual activity [6]. Dusing et al. reported reduction in ED with improved orgasmic function, intercourse and overal sexual satisfaction in a group of 2550 hypertensive patients treated with valsartan [51].

Angiotensin II is synthesised in the corpus cavernosum; it is involved in detumescence of the corpus cavernosum, and produces oxidative stress in the penile endothelium, thereby possibly promoting the development of ED [52].

In hypercholesterolaemic apolipoprotein E knockout mice, endothelial function of the corpus cavernosum as a surrogate for ED was improved in tandem with a reduction in aortic plaque load by ARB treatment [53]. Observational studies showed an increase in sexual activity in hypertensive subjects or patients with metabolic syndrome who were treated with an ACE inhibitor or ARB compared with patients with other therapies such as $\beta$-blockers $[47,48,52]$. No differences were seen between the use of ramipril, telmisartan or a combination of the two and there was no evidence for adverse effects of both treatments on erectile function [54]. The beneficial effects on sexual function were confirmed in a study among 2202 hypertensive patients, reporting an increase of sexual intercourse per week when treated with valsartan. A recent double-blind randomised study among 1549 patients in which 400 participants received ramipril, 395 telmisartan and 381 a combination of the two, no benefits of ARBs on erectile dysfunction were proven [55]. It was noted, however, that ARBs were added on top of the previous multidrug regime in high-risk patients and thus conclusions regarding the effects of ARB monotherapy cannot be drawn [56]. In recent randomised trials, irbesartan use after nerve-sparing prostatectomy in patients with normal preoperative erectile function was shown to improve erectile function recovery [57]. Losartan seemed to have positive effects on erectile function as well [58]. Concerning female sexual function, valsartan has been shown to improve sexual desire and sexual fantasies, while atenolol significantly worsened these items [18]. Likewise, women treated with the irbesartan-felodipine combination showed significantly higher FSFI scores than those treated with the metoprolol-felodipine combination [17].

Overall, ARBs seem to have beneficial effects on sexual function and, if possible, should be used in the treatment of patients complaining of sexual side effects from other cardiovascular agents, or in men with preexistent ED. 


\section{Calcium channel antagonists}

These agents increase dilatation and lower blood pressure by reducing calcium entry into the smooth muscle of the blood vessels [59]. Due to this mechanism of action, calcium antagonists are not expected to cause sexual dysfunction [7]. Indeed, in the TOMHS trial, amlodipine did not appear to affect sexual function [30], neither did nicardipine [60], nifedipine or diltiazem in other studies $[61,62]$. In two early studies, gynaecomastia and problems with ejaculation occurred in patients who received calcium channel blocker therapy, probably related to hyperprolactinaemia [9, 63]; this was never investigated in later studies. In a double-blind comparative study in 451 patients of both sexes, patients were allocated either to treatment with the calcium channel blocker amlodipine or with the ACE inhibitor enalapril for 50 weeks after a 4-week placebo run-in. Sexual function was not different between the two groups [61]. Taken together, the available data suggest that calcium channel antagonists do not a detrimental effect on sexual function.

Statins (3-hydroxy-3-methylglaryl-coenzyme A reductase inhibitors)

Cholesterol is the biochemical precursor for testosterone. An experimental study and an RCT showed reduced testosterone in men using a statin although the average effect is modest [64, 65]. Studies in small samples or with lower statin doses did not show significant changes in average testosterone levels [66]. An in vitro study demonstrated statin effects on human testicular testosterone synthesis [67] and in animals effects on the morphology and function of Leydig cells have been seen after statin administration [68]. In a prospective observational study among 93 men it was suggested that ED following statin therapy is more likely in patients with severe endothelial dysfunction due to established cardiovascular risk factors, including age, smoking and diabetes [69]. On the other hand, statins have been reported to improve erectile function when the cohorts had no other cardiovascular risk factors accept for untreated ED [70-72]. Furthermore, statins seem to increase the beneficial effects of sildenafil through endothelial function benefits [73-76]. These endothelial function benefits may rely on the antioxidant effects of statins [77, 78], which clearly predominate over the pro-oxidant effects [79]. On the whole, evidence shows that statins can have a beneficial effect on erectile function because the beneficial effects seem to be more powerful than the negative effects on the testosterone level [80].

\section{Discussion}

Based on the absence of hard data coming from randomised controlled studies, the Second Princeton Consensus Management
Recommendation states that 'a change in class of antihypertensive medication rarely results in the restoration of sexual function' [81]. However, the available data point towards significant benefits in sexual function when switching prior antihypertensive therapy $[4,48,51,82]$. This review demonstrated that significant improvements in male and female sexual function can be achieved when cardiovascular drug treatment is switched to either nebivolol or an ARB and that use of statins can improve sexual function. Also, several lines of evidence indicate that older-generation beta blockers, digoxin and diuretics can indeed decrease sexual function. This knowledge should become incorporated in cardiologist and general practitioner practices, because it is necessary to be able to offer patients a tailor-made medical treatment, to avoid or diminish side effects and thus improve compliance with therapy.

For this review we used RCTs together with double-blind crossover studies, observational and questionnaire studies. The impact of the studies was not scored or indexed for; consequently, definite conclusions cannot be inferred from this review. It should be kept in mind that more than twothirds of hypertensive patients require combination therapy of at least two drugs to reach their blood pressure goals. Therefore, in the future combination therapy or therapeutic strategies will have to be compared with respect to their effects on sexual function [28]. Nevertheless, hard data from large randomised controlled trials regarding the switch of cardiovascular drugs in monotherapy or multidrug regimens for the benefit of sexual function are lacking. This review can therefore be helpful for cardiologists, urologists, general practitioners and other healthcare professionals who deal with patients complaining of sexual dysfunction during treatment with cardiovascular agents. The overview table shows clearly which effects were found in the numerous studies that have been performed until know.

Poor adherence in antihypertensive drug therapy is a critical contributor to unsatisfactory blood pressure control rates and erectile dysfunction has been shown to contribute to poor adherence [4]. Management of sexual dysfunction induced by hypertension and its related medication represents a challenge in everyday clinical practice. For patients presenting with sexual dysfunction during cardiovascular drug therapy, lifestyle modification and switching medication according to the information conveyed above should be the first line of action unless the current treatment is absolutely indicated [83]. Since ARBs are now generic, they should be considered as first-line therapy in men for whom erectile function is important (most men), rather than relying on switching in the case they are brave enough to mention ED. If there is no advantage for treatment of ACE inhibitors above ARBs, we suggest ARBs should be considered first-line therapy, instead of allowing sexual dysfunction to happen and then prescribe a (self-funded) PDE-5 inhibitor, because this is not a satisfactory solution for most patients. However, in males with persisting erectile dysfunction 
(and despite the use of ARBs) PDE-5 inhibitors should be offered as the next step, since they exert beneficial effects through improved adherence. It was shown that hypertensive men with erectile dysfunction are more likely to initiate rather than discontinue and add rather than reject antihypertensive medication when receiving PDE-5 inhibitors [84].

Literature about the effects of antihypertensive drugs in female sexual function is limited, but findings from small observational and clinical studies point towards similar effects of antihypertensive drugs in male and female sexual function $[4,16,85]$. Female cardiac patients presenting with sexual dysfunction should receive the same treatment and advice as male patients concerning lifestyle modifications. And, if not contraindicated, ARBs should be considered as first-line therapy in females too, as literature points to benefits of ARBs compared with beta-blockers in female sexual function. If these measures are insufficient, a referral to a sexologist or a gynaecologist can be the considered.

As was seen in the evaluation of cardiologists concerning their knowledge and practice patterns in regard to sexual dysfunction [86] and the sexual side effects of cardiovascular medication [5] cardiologists lack the knowledge and training to provide the solutions and advice necessary to ameliorate patients' sexual function and with that, to ensure adherence to cardiovascular treatment. In our opinion, appropriate education of cardiologists and other involved healthcare professionals is needed to overcome this problem. Furthermore, sexual effects of cardiovascular medication in both male and female dysfunction is a broad area for future research; in the meanwhile the proposed overview table can be of help in the clinical setting.

Open Access This article is distributed under the terms of the Creative Commons Attribution License which permits any use, distribution, and reproduction in any medium, provided the original author(s) and the source are credited.

\section{References}

1. IMS Institute for Healthcare Informatics. The use of medicines in the united states, review of 2010. Update april 2011: http://www. imshealth.com/deployedfiles/imshealth/Global/Content/IMS\% 20Institute/Static\%20File/IHII UseOfMed report.pdf.

2. Burchardt M, Burchardt T, Baer L, et al. Hypertension is associated with severe erectile dysfunction. J Urol. 2000;164(4):1188-91.

3. Rosen RC. Sexual dysfunction as an obstacle to compliance with antihypertensive therapy. Blood Press Suppl. 1997;1:47-51.

4. Manolis A, Doumas M. Antihypertensive treatment and sexual dysfunction. Curr Hypertens Rep. 2012;14(4):285-92.

5. Nicolai MPJ, Liem SS, Both S, et al. What do cardiologists know about the effects of cardiovascular drugs on sexual function? A survey among Dutch cardiologists. Neth Heart J. 2013.

6. Fogari R, Zoppi A, Poletti L, et al. Sexual activity in hypertensive men treated with valsartan or carvedilol: a crossover study. Am J Hypertens. 2001;14(1):27-31.
7. Fogari R, Zoppi A. Effects of antihypertensive therapy on sexual activity in hypertensive men. Curr Hypertens Rep. 2002;4(3):202-10.

8. Bauer GE, Baker J, Hunyor SN, et al. Side-effects of antihypertensive treatment: a placebo-controlled study. Clin Sci Mol Med Suppl. $1978 ; 4: 341 \mathrm{~s}-4 \mathrm{~s}$.

9. Suzuki H, Tominaga T, Kumagai H, et al. Effects of first-line antihypertensive agents on sexual function and sex hormones. J Hypertens Suppl. 1988;6(4):S649-51.

10. Barksdale JD, Gardner SF. The impact of first-line antihypertensive drugs on erectile dysfunction. Pharmacotherapy. 1999;19(5):573-81.

11. Fogari R, Preti P, Derosa G, et al. Effect of antihypertensive treatment with valsartan or atenolol on sexual activity and plasma testosterone in hypertensive men. Eur J Clin Pharmacol. 2002;58(3):177-80.

12. Franzen D, Metha A, Seifert N, et al. Effects of beta-blockers on sexual performance in men with coronary heart disease. A prospective, randomized and double blinded study. Int J Impot Res. 2001;13(6):348-51.

13. Perez-Stable EJ, Halliday R, et al. The effects of propranolol on cognitive function and quality of life: a randomized trial among patients with diastolic hypertension. Am J Med. 2000;108(5):359-65.

14. Silvestri A, Galetta P, Cerquetani E, et al. Report of erectile dysfunction after therapy with beta-blockers is related to patient knowledge of side effects and is reversed by placebo. Eur Heart J. 2003;24(21):1928-32.

15. Wassertheil-Smoller S, Blaufox MD, Oberman A, et al. Effect of antihypertensives on sexual function and quality of life: the TAIM Study. Ann Intern Med. 1991;114(8):613-20.

16. Doumas M, Tsiodras S, Tsakiris A, et al. Female sexual dysfunction in essential hypertension: a common problem being uncovered. $\mathrm{J}$ Hypertens. 2006;24(12):2387-92.

17. Ma R, Yu J, Xu D, et al. Effect of felodipine with irbesartan or metoprolol on sexual function and oxidative stress in women with essential hypertension. J Hypertens. 2012;30(1):210-6.

18. Fogari R, Preti P, Zoppi A, et al. Effect of valsartan and atenolol on sexual behavior in hypertensive postmenopausal women. Am J Hypertens. 2004;17(1):77-81.

19. Ko DT, Hebert PR, Coffey CS, et al. Beta-blocker therapy and symptoms of depression, fatigue, and sexual dysfunction. JAMA. 2002;288(3):351-7.

20. Erdmann E. Safety and tolerability of beta-blockers: prejudices \& reality. Indian Heart J. 2010;62(2):132-5.

21. Heart Foundation. Guide to management of hypertension 2008-2010. [http://www.heartfoundation.org.au/SiteCollectionDocuments/ HypertensionGuidelines2008to2010Update.pdf]. 2012.

22. Hackett G, Kell P, Ralph D, et al. British Society for Sexual Medicine guidelines on the management of erectile dysfunction. J Sex Med. 2008;5(8):1841-65.

23. Karavitakis M, Komninos C, Theodorakis PN, et al. Evaluation of sexual function in hypertensive men receiving treatment: a review of current guidelines recommendation. J Sex Med. 2011;8(9):2405-14.

24. Doumas M, Tsakiris A, Douma S, et al. Beneficial effects of switching from beta-blockers to nebivolol on the erectile function of hypertensive patients. Asian J Androl. 2006;8(2):177-82.

25. Cheng JW. Nebivolol: a third-generation beta-blocker for hypertension. Clin Ther. 2009;31(3):447-62.

26. Brixius K, Middeke M, Lichtenthal A, et al. Nitric oxide, erectile dysfunction and beta-blocker treatment (MR NOED study): benefit of nebivolol versus metoprolol in hypertensive men. Clin Exp Pharmacol Physiol. 2007;34(4):327-31.

27. Baumhakel M, Schlimmer N, Kratz M, et al. Cardiovascular risk, drugs and erectile function-a systematic analysis. Int J Clin Pract. 2011;65(3):289-98.

28. Dusing R. Sexual dysfunction in male patients with hypertension: influence of antihypertensive drugs. Drugs. 2005;65(6):773-86.

29. Adverse reactions to bendrofluazide and propranolol for the treatment of mild hypertension. Report of Medical Research Council Working Party on Mild to Moderate Hypertension. Lancet 1981 Sep 12;2(8246):539-43. 
30. Grimm Jr RH, Grandits GA, Prineas RJ, et al. Long-term effects on sexual function of five antihypertensive drugs and nutritional hygienic treatment in hypertensive men and women. Treatment of Mild Hypertension Study (TOMHS). Hypertension. 1997;29(1 Pt 1):8-14.

31. Bulpitt CJ, Dollery CT. Side effects of hypotensive agents evaluated by a self-administered questionnaire. Br Med J. 1973;3(5878): 485-90.

32. Chang SW, Fine R, Siegel D, et al. The impact of diuretic therapy on reported sexual function. Arch Intern Med. 1991;151(12):2402-8.

33. Lindholm LH, Persson M, Alaupovic P, et al. Metabolic outcome during 1 year in newly detected hypertensives: results of the Antihypertensive Treatment and Lipid Profile in a North of Sweden Efficacy Evaluation (ALPINE study). J Hypertens. 2003;21(8): $1563-74$.

34. Duncan L, Bateman DN. Sexual function in women. Do antihypertensive drugs have an impact? Drug Saf. 1993;8(3):225-34.

35. Epstein M, Calhoun DA. Aldosterone blockers (mineralocorticoid receptor antagonism) and potassium-sparing diuretics. J Clin Hypertens (Greenwich). 2011;13(9):644-8.

36. Pitt B, Zannad F, Remme WJ, et al. The effect of spironolactone on morbidity and mortality in patients with severe heart failure. Randomized Aldactone Evaluation Study Investigators. N Engl J Med. 1999;341(10):709-17.

37. Pitt B, Remme W, Zannad F, et al. Eplerenone, a selective aldosterone blocker, in patients with left ventricular dysfunction after myocardial infarction. N Engl J Med. 2003;348(14):1309-21.

38. van Dijk MM, de la Rosette JJ, Michel MC. Effects of alpha(1)adrenoceptor antagonists on male sexual function. Drugs. 2006;66(3):287-301.

39. AUA guideline on management of benign prostatic hyperplasia (2003). Chapter 1: Diagnosis and treatment recommendations. J Urol 2003 Aug; 170(2 Pt 1):530-47.

40. Hellstrom WJ, Giuliano F, Rosen RC. Ejaculatory dysfunction and its association with lower urinary tract symptoms of benign prostatic hyperplasia and BPH treatment. Urology. 2009;74(1):15-21.

41. Gupta S, Salimpour P, SaenzdeTejada I, et al. A possible mechanism for alteration of human erectile function by digoxin: inhibition of corpus cavernosum sodium/potassium adenosine triphosphatase activity. J Urol. 1998;159(5):1529-36.

42. Stoffer SS, Hynes KM, Jiang NS, et al. Digoxin and abnormal serum hormone levels. JAMA. 1973;225(13):1643-4.

43. Neri A, Zukerman Z, Aygen M, et al. The effect of long-term administration of digoxin on plasma androgens and sexual dysfunction. J Sex Marital Ther. 1987;13(1):58-63.

44. Bellmann O, Ochs HR, Knuchel M, et al. Evaluation of the hypothalamic-pituitary effects of digoxin. J Clin Pharmacol. 1984;24(11-12):474-9.

45. Kley HK, Abendroth H, Hehrmann R, et al. No effect of digitalis on sex and adrenal hormones in healthy subjects and in patients with congestive heart failure. Klin Wochenschr. 1984;62(2):65-73.

46. Kley HK, Muller A, Peerenboom H, et al. Digoxin does not alter plasma steroid levels in health men. Clin Pharmacol Ther. 1982;32(1):12-7.

47. Fogari R, Zoppi A, Corradi L, et al. Sexual function in hypertensive males treated with lisinopril or atenolol: a cross-over study. Am J Hypertens. 1998;11(10):1244-7.

48. Baumhakel M, Schlimmer N, Bohm M. Effect of irbesartan on erectile function in patients with hypertension and metabolic syndrome. Int J Impot Res. 2008;20(5):493-500.

49. Rastogi S, Rodriguez JJ, Kapur V, et al. Why do patients with heart failure suffer from erectile dysfunction? A critical review and suggestions on how to approach this problem. Int J Impot Res. 2005;17 Suppl 1:S25-36.

50. Mancini GB, Henry GC, Macaya C, et al. Angiotensin-converting enzyme inhibition with quinapril improves endothelial vasomotor dysfunction in patients with coronary artery disease. The TREND
(Trial on Reversing ENdothelial Dysfunction) Study. Circulation. 1996;94(3):258-65.

51. Dusing R. Effect of the angiotensin II antagonist valsartan on sexual function in hypertensive men. Blood Press Suppl. 2003;2:29-34.

52. Becker AJ, Uckert S, Stief CG, et al. Possible role of bradykinin and angiotensin II in the regulation of penile erection and detumescence. Urology. 2001;57(1):193-8.

53. Baumhakel M, Custodis F, Schlimmer N, et al. Improvement of endothelial function of the corpus cavernosum in apolipoprotein $\mathrm{E}$ knockout mice treated with irbesartan. J Pharmacol Exp Ther. 2008;327(3):692-8.

54. Kroner BA, Mulligan T, Briggs GC. Effect of frequently prescribed cardiovascular medications on sexual function: a pilot study. Ann Pharmacother. 1993;27(11):1329-32.

55. Bohm M, Baumhakel M, Teo K, et al. Erectile dysfunction predicts cardiovascular events in high-risk patients receiving telmisartan, ramipril, or both: The ONgoing Telmisartan Alone and in combination with Ramipril Global Endpoint Trial/Telmisartan Randomized AssessmeNt Study in ACE iNtolerant subjects with cardiovascular Disease (ONTARGET/TRANSCEND) Trials. Circulation. 2010;121(12):1439-46.

56. Viigimaa M, Doumas M, Vlachopoulos C, et al. Hypertension and sexual dysfunction: time to act. J Hypertens. 2011;29(2):403-7.

57. Segal RL, Bivalacqua TJ, Burnett AL. Irbesartan promotes erection recovery after nerve-sparing radical retropubic prostatectomy: a retrospective long-term analysis. BJU Int. 2012;110(11):1782-6.

58. Chen Y, Cui S, Lin H, et al. Losartan improves erectile dysfunction in diabetic patients: a clinical trial. Int J Impot Res. 2012;24(6):217-20.

59. Kochar MS, Mazur LI, Patel A. What is causing your patient's sexual dysfunction? Uncovering a connection with hypertension and antihypertensive therapy. Postgrad Med. 1999;106(2):149-7.

60. Ogihara T, Kuramoto K. Effect of long-term treatment with antihypertensive drugs on quality of life of elderly patients with hypertension: a double-blind comparative study between a calcium antagonist and a diuretic. NICS-EH Study Group. National Intervention Cooperative Study in Elderly Hypertensives. Hypertens Res. 2000;23(1):33-7.

61. Omvik P, Thaulow E, Herland OB, et al. Double-blind, parallel, comparative study on quality of life during treatment with amlodipine or enalapril in mild or moderate hypertensive patients: a multicentre study. J Hypertens. 1993;11(1):103-13.

62. Kroner BA, Mulligan T, Briggs GC. Effect of frequently prescribed cardiovascular medications on sexual function: a pilot study. Ann Pharmacother. 1993;27(11):1329-32.

63. Tanner LA, Bosco LA. Gynecomastia associated with calcium channel blocker therapy. Arch Intern Med. 1988;148(2):379-80.

64. Azzarito C, Boiardi L, Vergoni W, et al. Testicular function in hypercholesterolemic male patients during prolonged simvastatin treatment. Horm Metab Res. 1996;28(4):193-8.

65. Hyyppa MT, Kronholm E, Virtanen A, et al. Does simvastatin affect mood and steroid hormone levels in hypercholesterolemic men? A randomized double-blind trial. Psychoneuroendocrinology. 2003;28(2):181-94.

66. Golomb BA, Evans MA. Statin adverse effects : a review of the literature and evidence for a mitochondrial mechanism. Am J Cardiovasc Drugs. 2008;8(6):373-418.

67. Smals AG, Weusten JJ, Benraad TJ, et al. The HMG-CoA reductase inhibitor simvastatin suppresses human testicular testosterone synthesis in vitro by a selective inhibitory effect on 17-ketosteroid-oxidoreductase enzyme activity. J Steroid Biochem Mol Biol. 1991;38(4):465-8.

68. Andreis PG, Cavallini L, Mazzocchi G, et al. Effects of prolonged administration of lovastatin, an inhibitor of cholesterol synthesis, on the morphology and function of rat Leydig cells. Exp Clin Endocrinol. 1990;96(1):15-24.

69. Solomon H, Samarasinghe YP, Feher MD, et al. Erectile dysfunction and statin treatment in high cardiovascular risk patients. Int J Clin Pract. 2006;60(2):141-5. 
70. Saltzman EA, Guay AT, Jacobson J. Improvement in erectile function in men with organic erectile dysfunction by correction of elevated cholesterol levels: a clinical observation. J Urol. 2004;172(1):255-8.

71. Dogru MT, Basar MM, Simsek A, et al. Effects of statin treatment on serum sex steroids levels and autonomic and erectile function. Urology. 2008;71(4):703-7.

72. Trivedi D, Kirby M, Wellsted DM, et al. Can simvastatin improve erectile function and health-related quality of life in men aged $>/=40$ years with erectile dysfunction? Results of the Erectile Dysfunction and Statins Trial [ISRCTN66772971]. BJU Int. 2013;111(2):324-33.

73. Herrmann HC, Levine LA, Macaluso J, et al. Can atorvastatin improve the response to sildenafil in men with erectile dysfunction not initially responsive to sildenafil? Hypothesis and pilot trial results. J Sex Med. 2006;3(2):303-8.

74. Saltzman EA, Guay AT, Jacobson J. Improvement in erectile function in men with organic erectile dysfunction by correction of elevated cholesterol levels: a clinical observation. J Urol. 2004;172(1):255-8.

75. Castro MM, Rizzi E, Rascado RR, et al. Atorvastatin enhances sildenafil-induced vasodilation through nitric oxide-mediated mechanisms. Eur J Pharmacol. 2004;498(1-3):189-94.

76. Dadkhah F, Safarinejad MR, Asgari MA, et al. Atorvastatin improves the response to sildenafil in hypercholesterolemic men with erectile dysfunction not initially responsive to sildenafil. Int J Impot Res. 2010;22(1):51-60.

77. Haendeler J, Hoffmann J, Zeiher AM, et al. Antioxidant effects of statins via S-nitrosylation and activation of thioredoxin in endothelial cells: a novel vasculoprotective function of statins. Circulation. 2004;110(7):856-61.
78. Grosser N, Hemmerle A, Berndt G, et al. The antioxidant defense protein heme oxygenase 1 is a novel target for statins in endothelial cells. Free Radic Biol Med. 2004;37(12):2064-71.

79. Sinzinger H, Chehne F, Lupattelli G. Oxidation injury in patients receiving HMG-CoA reductase inhibitors: occurrence in patients without enzyme elevation or myopathy. Drug Saf. 2002;25(12):877-83.

80. Trivedi D, Kirby M, Wellsted DM, et al. Can simvastatin improve erectile function and health-related quality of life in men aged $>/=40$ years with erectile dysfunction? Results of the Erectile Dysfunction and Statins Trial [ISRCTN66772971]. BJU Int 2012 Jun 11.

81. Kostis JB, Jackson G, Rosen R, et al. Sexual dysfunction and cardiac risk (the Second Princeton Consensus Conference). Am J Cardiol. 2005;96(2):313-21.

82. Della CA, Pfiffner D, Meier B, et al. Sexual activity in hypertensive men. J Hum Hypertens. 2003;17(8):515-21.

83. Doumas M, Douma S. The effect of antihypertensive drugs on erectile function: a proposed management algorithm. J Clin Hypertens (Greenwich). 2006;8(5):359-64.

84. McLaughlin T, Harnett J, Burhani S, et al. Evaluation of erectile dysfunction therapy in patients previously nonadherent to long-term medications: a retrospective analysis of prescription claims. Am J Ther. 2005;12(6):605-11.

85. Fogari R, Preti P, Zoppi A, et al. Effect of valsartan and atenolol on sexual behavior in hypertensive postmenopausal women. Am J Hypertens. 2004;17(1):77-81.

86. Nicolai MP, Both S, Liem SS, et al. Discussing sexual function in the cardiology practice. Clin Res Cardiol 2013 Feb 8. 